\title{
Paramagnetism and Relaxation Dynamics in Melanin Biomaterials
}

\section{Supporting Information}

Maher Al Khatib, Jessica Costa, Maria Camilla Baratto, Riccardo Basosi, and Rebecca Pogni* Department of Biotechnology, Chemistry and Pharmacy, Via A. Moro 2, 53100 Siena (Italy)

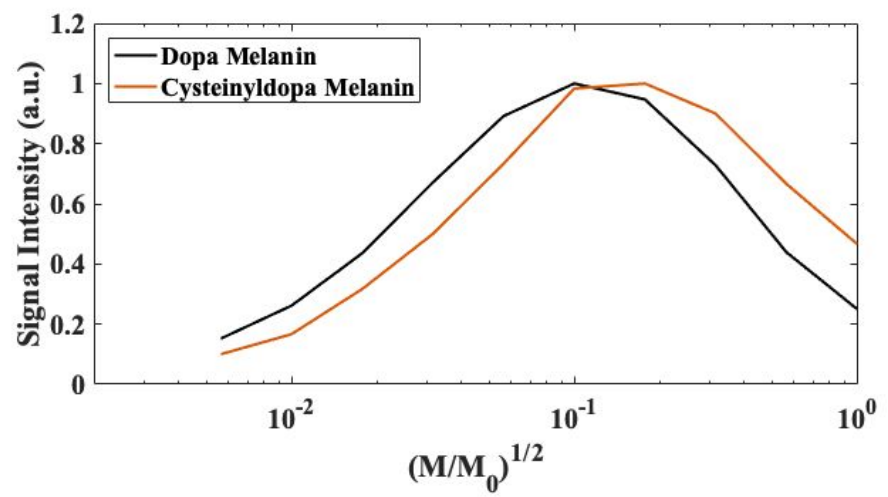

Figure S1 X-band CW saturation curves for the dopa melanin $(v=9.871 \mathrm{GHz})$ and cysteinyldopa melanin $(v=9.877 \mathrm{GHz})$. Maximum reference microwave power $\mathrm{M}_{0}=144.5 \mathrm{~mW}$

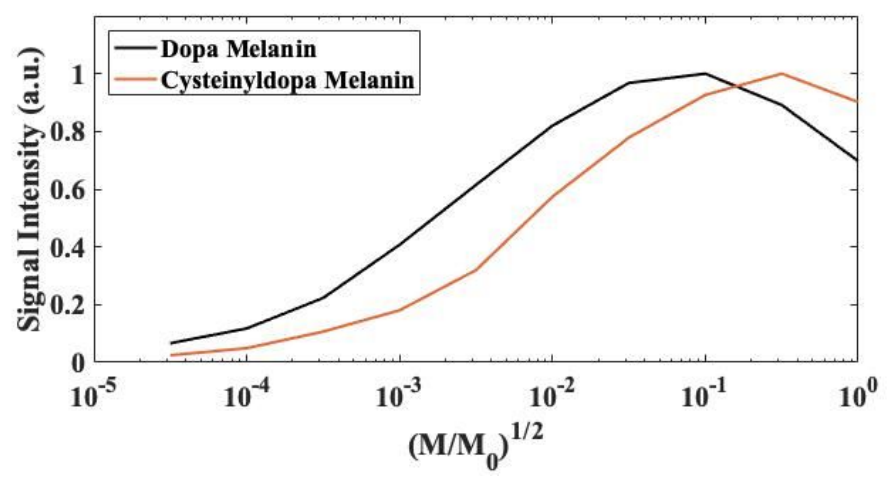

Figure S2 Q-band CW saturation curves for the dopa melanin $(\boldsymbol{v}=33.843 \mathrm{GHz})$ and cysteinyldopa melanin $(v=33.733 \mathrm{GHz})$. Maximum reference microwave power $\mathrm{M}_{0}=6.3 \mathrm{~mW}$. 


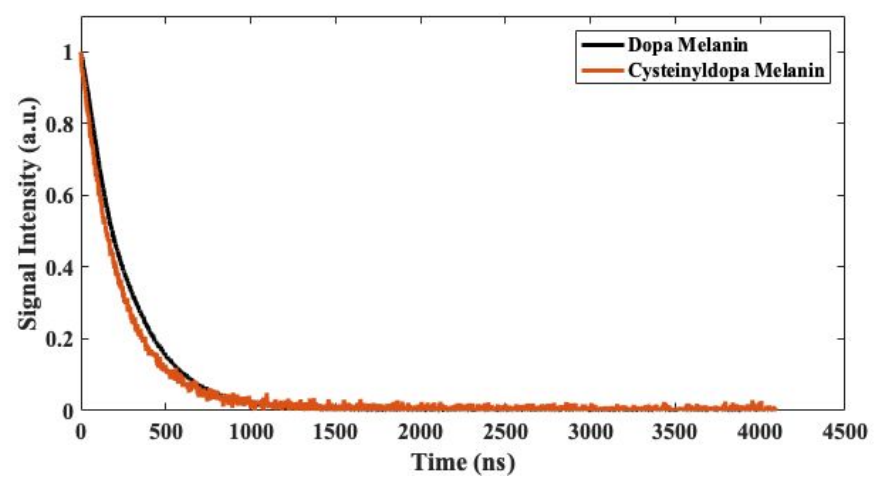

Figure S3 Phase memory time $\left(\mathrm{T}_{\mathrm{M}}\right)$ measurements for the dopa melanin and cysteinyldopa melanin samples were performed with $\pi / 2-\tau-\pi$ echo detection sequence with increasing $\tau$ values $(\pi / 2=42 \mathrm{~ns}$ and $\pi=84 \mathrm{~ns}$ ) 